Provided for non-commercial research and education use. Not for reproduction, distribution or commercial use.

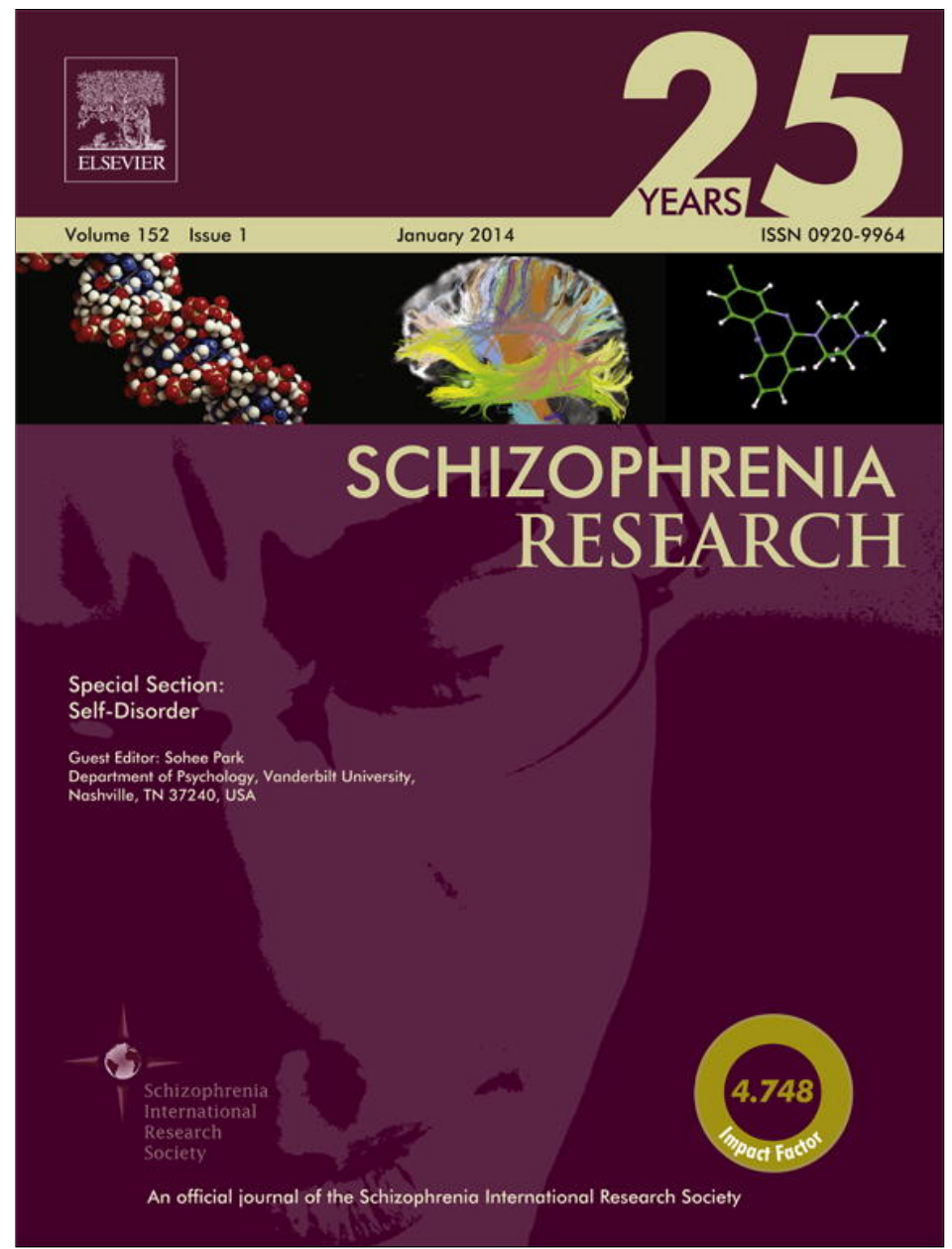

This article appeared in a journal published by Elsevier. The attached copy is furnished to the author for internal non-commercial research and education use, including for instruction at the authors institution and sharing with colleagues.

Other uses, including reproduction and distribution, or selling or licensing copies, or posting to personal, institutional or third party websites are prohibited.

In most cases authors are permitted to post their version of the article (e.g. in Word or Tex form) to their personal website or institutional repository. Authors requiring further information regarding Elsevier's archiving and manuscript policies are encouraged to visit:

http://www.elsevier.com/authorsrights 


\title{
Failing to self-ascribe thought and motion: Towards a three-factor account of passivity symptoms in schizophrenia
}

\author{
David Miguel Gray* \\ Colgate University, Department of Philosophy, 13 Oak Drive, Hamilton, NY 13346-1398, United States
}

\section{A R T I C L E I N F O}

\section{Article history:}

Received 12 March 2013

Received in revised form 13 June 2013

Accepted 14 June 2013

Available online 6 July 2013

\section{Keywords:}

Alien control

Cognitive phenomenology

Corollary discharge

Delusion

Efferent copy

Monothematic delusion

Passivity symptoms

Polythematic delusion

Schizophrenia

Thought insertion

\begin{abstract}
A B S T R A C T
There has recently been emphasis put on providing two-factor accounts of monothematic delusions. Such accounts would explain (1) whether a delusional hypothesis (e.g. someone else is inserting thoughts into my mind) can be understood as a prima facie reasonable response to an experience and (2) why such a delusional hypothesis is believed and maintained given its implausibility and evidence against it. I argue that if we are to avoid obfuscating the cognitive mechanisms involved in monothematic delusion formation we should split the first factor ( 1 above) into two factors: how abnormal experience can give rise to a delusional 'proto-hypothesis' and how a 'proto-hypothesis' in consort with normal experiences and background information, can be developed into a delusional hypothesis. In particular I will argue that a schizophrenic is faced with the unusual requirement of having to identify an introspectively accessible thought as one's own, and that this requirement of identification is the central experiential abnormality of thought insertion, auditory verbal hallucination, and alien control (i.e. passivity symptoms). Additionally, I will consider non-experiential factors which are required for the formation of a delusional hypothesis.
\end{abstract}

(c) 2013 Elsevier B.V. All rights reserved.

\section{Background/introduction}

Schizophrenia has attracted attention from philosophers of mind and philosophers of cognitive psychology largely because the passivity symptoms of thought insertion and alien control challenge some of the most intuitive beliefs we have about what is an adequate source of justification for our self-knowledge. (I will take 'self-knowledge' to mean introspection-based knowledge of one's thoughts and actions.) The intuitive view is that if I receive information about my own thoughts and movements on the basis of introspective information, this is sufficient to know (1) what sort of thinking or action I am engaged in and (2) that it is me who is doing the thinking and acting. However, the schizophrenic symptoms of thought insertion and alien control appear to bring the second claim into question: that introspective information is sufficient for knowing it is me who is doing the thinking and acting, and not someone else (e.g. see Campbell, 1999).

My aim in this article is to provide an explanation of abnormal experience for the passivity symptoms of schizophrenia. I will argue that what is essential to understanding these symptoms is that they result from an unusual requirement placed on the schizophrenic: a need to identify who is the agent of one's own thoughts and actions. I will

\footnotetext{
* Tel.: +1 6173653469 .

E-mail address: dgray@colgate.edu.
}

argue that this requirement of identification is the central feature of the abnormal experience associated with passivity symptoms. As I take the fundamental aspects of the abnormal experience underlying passivity symptoms to be the same, I will focus my attention on thought insertion-mentioning alien control and auditory verbal hallucination when discussion of such cases is helpful. I will offer this explanation by expanding on a 'two-factor' account used to explain delusions by Davies and Coltheart (2000).

\section{Monothematic delusions, two-, and three-factor accounts}

As noted by Davies and Coltheart (2000) several delusions can be categorized as monothematic in that they focus on a central theme (Davies et al., 2001). Examples of monothematic delusions include Capgras Delusion (the belief that individuals close to the person have been replaced by imposters) reduplicative paramnesia (an arm [attached to me] is someone else's and that person has three arms), the Cotard Delusion (the belief that I am dead), thought insertion, and alien control. Monothematic delusions are contrasted with polythematic delusions which focus on several themes and interact significantly with one's other beliefs. Schizophrenia often involves several kinds of delusions, including polythematic paranoid delusions. However, Davies and Coltheart are not attempting to characterize mental disorders such as schizophrenia, but rather the feasibility 
of a general framework for explaining delusions which focus on a central theme.

Davies' and Coltheart's project is thus significantly different than projects concerning etiological explanations of particular syndromes. For instance, Capgras Delusion has been witnessed in subjects with several disorders, including AIDS, Alzheimer's disease, epilepsy, Lewy-body dementia, multiple sclerosis, pituitary tumor, schizophrenia, and viral encephalitis (Coltheart et al., 2007). Regardless of the different neuropathologies that give rise to similar delusional claims, we can still provide a uniform cognitive explanation as to why delusions focusing on a central theme are made.

The two-factor account of monothematic delusions requires of cognitive accounts of monothematic delusions that they address the following two claims. In regards to any delusional hypothesis we must explain:

1. why a delusional hypothesis is a "prima facie reasonable response to the subject's experience", and

2. how one can adopt and maintain a delusional hypothesis given its "utter implausibility and the uniform skepticism with which other people greet it?" (Davies and Coltheart, 2000).

The two-factor account assumes that monothematic delusions have their origins in abnormal experience. Thus, there is the common presumption that monothematic delusions cannot result solely from abnormal reasoning. Among those who hold that monothematic delusions result from abnormal experience, researchers are divided into those that think delusional beliefs are rational responses to abnormal experience (e.g. Maher, 1974, 1988, 1992, 1999) and those who think that delusional beliefs are irrational responses to abnormal experience (e.g. Stone and Young, 1997; Davies and Coltheart, 2000; Coltheart et al., 2007; Coltheart, 2013). While both camps are capable of giving two-factor accounts, the first camp will explain the second factor in terms of normal reasoning and continuing abnormal experience $^{1}$ whereas the second camp will explain the second factor in terms of abnormal reasoning alone. (As my concern is just with abnormal experience and how it can lead to the formation of a delusional hypothesis I will elaborate primarily on the first factor.)

Granting this central role given to abnormal experience in accounting for delusion formation, we might ask how a delusional hypothesis can be a prima facie reasonable response to an abnormal experience. I take the demands on what makes a response to an abnormal experience prima facie reasonable to be quite minimal. For instance, having a hallucination of a miniature pink elephant provides one with prima facie reason for believing that there is a pink elephant. Of course, this belief is easily defeated by other considerations - that's why it is just a prima facie reasonable response. However, having a hallucination of a pink elephant does not provide me with prima facie reason for believing that good golfers make horrible mathematicians. We might say that in order for a response to an experience to be prima facie reasonable, the response (e.g. a belief or hypothesis), has to adequately represent the experience the individual is presented with. This account of prima facie reasonableness places the following explanatory burden on us: whatever account of abnormal experience is given, we must be able to give an account of it such that some delusional hypotheses can be

\footnotetext{
${ }^{1}$ Maher has theorized that it is repeated abnormal experiences that result in the formation and maintenance of delusional beliefs. As such, he accounts for the first and second factor of monothematic delusions by appealing to abnormal experience (Maher, 1999, 566). In what follows, I agree with Maher in terms of accounting for the first factor: schizophrenics exhibit sufficient rationality, that the simplest explanation for the formulation of a delusional hypothesis need not invoke failures of rationality in addition to abnormal experience. For reasons beyond the scope of this paper, I do not think that the maintenance of delusional hypothesis can be given a similar 'rational' account given the tendency of delusional schizophrenics to adopt beliefs on the basis of minimal positive evidence (see e.g. Langdon et al., 2010; Moritz and Woodward, 2005; Colbert and Peters, 2002; Young and Bentall, 1997; Garety et al., 1991; Huq et al., 1988).
}

taken to adequately represent the experience whereas other hypotheses cannot.

A problem with the first factor of the two-factor account is that it has an ambiguity that can result in an explanatory inadequacy: the first factor does not disambiguate whether a proper explanation should be one which explains how the delusional hypothesis is a prima facie reasonable response to either (1) just an abnormal experience or (2) an abnormal experience in addition to normal experiences and background information. Problems arise if we adopt the first approach as it will demand a highly intricate abnormal experience to bring about the delusional hypothesis. We can see this demand in the following characterization of the abnormal experience involved in thought insertion:

One central phenomenon of the "psychosis of thinking"...is thought insertion ... in which the patient feels that alien thoughts are being inserted into his mind

[Campbell, 1999, 615.]

In this account, the abnormal experience is supposed to be captured by the description of the feeling 'that alien thoughts are being inserted into his mind'. If one could have a feeling which is properly described as 'alien thoughts are being inserted into my mind', then the delusional hypothesis 'alien thoughts are being inserted into my mind' would adequately represent that experience and thus be a prima facie reasonable response to this abnormal experience. But without a previous experience of (real) alien thoughts and (real) thought insertion, how would we be able to describe such a feeling? ${ }^{2}$

To reduce the demand for a highly intricate abnormal experience, as required by the former interpretation mentioned above, we can disambiguate the first factor in the following way:

0. What delusional proto-hypothesis can be understood as a prima facie reasonable response to the subject's abnormal experience?

$1^{\prime}$. How can we explain the development of a delusional hypothesis in light of the subject's delusional proto-hypothesis, inferences, normal experiences, and background information?

By 'proto-hypothesis' I mean a hypothesis which is a prima facie reasonable response to just the subject's abnormal experience. As such, a delusional proto-hypothesis serves as an explanatory intermediary between abnormal experience and the adopted delusional hypothesis. As such, there is no expectation that the delusional proto-hypothesis be explicitly entertained by the subject in question. The proto-hypothesis will aid in an explanation of what can be a reasonable response to an abnormal experience (captured by the 0 factor) and what inferences, normal experiences, and background assumptions can lead to the development of a delusional hypothesis (captured by the $1^{\prime}$ factor). ${ }^{3,4}$ Whereas this account allows us to posit a simpler (i.e. more plausible) abnormal experience than Campbell's account above, we must then do extra work to explain how a delusional hypothesis is formed.

\section{Passivity symptoms, explanatory challenges, and corollary discharge}

As I have now characterized the framework within which I will discuss monothematic delusions in schizophrenia, I will now address

\footnotetext{
${ }^{2}$ Contrast this with the task of describing an auditory verbal hallucination. While such hallucinatory experiences are often not experientially identical with hearing normal speech, such experiences can at least be approximately described by appeal to the ordinary experience of hearing speech.

${ }^{3}$ If there are cases where a delusional hypothesis can be formed solely on the basis of abnormal experience, the proto-hypothesis will just be the delusional hypothesis.

4 The factors on the three-factor account are labeled ' 0 ', ' 1 ', and '2'. I start with ' 0 ' so that the factor labeled ' 2 ', which is the same on both accounts, need not be relabeled. The second factor on the three-factor account is labeled ' 1 ' so as not to be confused with the first factor of the two-factor account labeled ' 1 '.
} 
a few challenges that should be met by an adequate explanation of the abnormal experience associated with passivity symptoms. Take the following report of thought insertion:

... it seemed to be her own thought "...but I don't get the feeling that it is." She said her "own thoughts might say the same thing ... but the feeling isn't the same ... the feeling is that it is somebody else's...."

[Allison-Bolger 1999, \#8, qtd. in Hoerl, 2001.]

This report is slightly atypical in that what is often expressed is the accepted delusional hypothesis that someone (in particular) is inserting thoughts into my head. Given the difficulty of attempting to explain an abnormal experience that most non-schizophrenics have never had, ${ }^{5} \mathrm{I}$ think that at least the following two explanatory challenges must be met.

First, on my revised three-factor approach, we must provide explanations for factors 0 and 1 ' separately. Second, the characterization of abnormal experience should be such that it can reasonably be seen as the result of a cognitive, as opposed to neurological, deficit. As the two- and three-factor accounts do not attempt to address the etiologies that give rise to delusions, defenders of these accounts are not required to provide a non-cognitive explanation of passivity symptoms. Before addressing these challenges, I will outline what I take to be the cognitive deficit involved in passivity symptoms that the abnormal experience must be correlated with.

The leading model used to account for the cognitive deficit associated with passivity symptoms posits a failure of self-monitoring (i.e. corollary discharge/efferent copy theory). We can find a highly elaborated version of this model in Frith (1992), although the attempt to explain thought insertion in terms of failures of self monitoring can first be found in Feinberg (1978). ${ }^{6}$ The idea of corollary discharge being central to explanations of passivity symptoms is still a popular approach being pursued in psychopathology research, e.g. Whitford et al., 2012 and Thakkar et al., 2013. ${ }^{7}$

Here is a version of the corollary discharge/efferent copy theory for passivity symptoms. Thought, subvocalization, and bodily movement are all, at least partially, the results of unconscious generative instruction. When these instructions generate thought, subvocalizations, or bodily movement, an efferent copy (i.e. a corollary discharge) of these instructions is made and sent to a comparator. Once the 'action' is performed (i.e., a thought, a subvocalization, or a bodily movement), feedback on how this action is being performed (reafferent information) is also sent to the comparator. When the information in these two streams of information 'matches' thoughts, subvocalizations, and bodily movements are experienced as one's own. ${ }^{8}$ However, in schizophrenics, the information in the efferent copy is delayed (Whiteford et al., 2012) in its arrival to the comparator. Nevertheless, the reafferent information

\footnotetext{
${ }^{5}$ Karl Jaspers (1923/1963, 93-104) had this concern as well: if it is not possible to empathize with schizophrenics' abnormal experiences, what chance do we have of understanding those experiences?

6 There have been substantial attempts to modify Frith et al.'s (2000) model of the neurocognitive action self-monitoring system in order to account for auditory verbal hallucination in Seale et al., 2004; and Jones and Fernyhough, 2007. While Frith (Frith and Gallagher, 2002) no longer endorses his 1992 model, I take it to be essentially correct in placing deficits of self-monitoring at the center of an explanation of abnormal phenomenology of passivity symptoms.

7 Thakkar et al. (2013) in particular have provided excellent functional evidence for corollary discharge malfunction in the oculomotor system of schizophrenics with positive symptoms.

${ }^{8}$ And at least in the case of bodily movement, when there are slight mismatches, e.g. when the reafferent information suggests the action is deviating from the original instructions, new instructions are sent to readjust the actions being performed (Megaw, 1972). Regardless of the slight mismatch, the actions are still taken to be one's own. Nasrallah (2012) has helpfully suggested that we can think of a breakdown of selfmonitoring as a breakdown of mental proprioception, analogous to physical proprioception. This aids us in explaining how thought insertion, like alien control, can result from a breakdown of self-monitoring.
}

does arrive at the comparator 'on time'. It is posited that this lack of matching information is what correlates with the abnormal experience in passivity symptoms.

In Sections 4 and 5, I will provide an explanation of the abnormal experience that gives rise to passivity symptoms, explain how these experiences can be the source of a prima facie reasonable delusional proto-hypothesis, how that proto-hypothesis can lead to a delusional hypothesis, and why the positive account of abnormal experience that I give can be plausibly correlated to the corollary discharge/efferent copy deficit in schizophrenia.

\section{From the top, down: arguing for a characterization of abnormal experience}

As I expressed earlier (fn. 2), I believe that part of an account of how a delusional hypothesis is generated will involve a delusional protohypothesis and reasonable inferences from that proto-hypothesis to a delusional hypothesis. As such, the strategy I will use here is to first 'explain away' features of the delusional hypothesis that can be explained in terms of rational inferences. Doing so will allow us to arrive upon a proto-hypothesis. I will then be able to provide a minimally intricate characterization of what the abnormal experience must be like if we are to account for the delusional proto-hypothesis. In Section 5, I will explain how this characterization can be plausibly correlated with our explanation of cognitive deficit.

Take the delusional belief that a thought in my head is my brother Bob's thought. I might think that it is Bob inserting thoughts into my head because the thought has a content like 'this is Bob' or some other content that would be the kind of thought that Bob might express to me. Alternatively, my thought might be accompanied with auditory imagery that makes it as if Bob were talking to me. These features of thought could lead me to believe that this thought in my head that is not mine is in fact Bob's thought. Without these explanations which allow us to ascribe the thought to a particular person, we are left with the simpler delusional claim that a thought in my head is somebody else's.

However, this simpler delusion hypothesis, i.e. that a thought in my head is someone else's, can also be 'explained away'. In virtue of having introspective access to a thought, I can reasonably claim that the thought I am experiencing is 'in my head'. However, if I also think the thought isn't mine, but there is nevertheless a thought in my head, it stands to reason that it is somebody else's. Thoughts, after all, have to have thinkers.

We are now left with a simpler delusional claim: that a thought I am introspectively experiencing is not mine. Even this hypothesis is still too robust to be a prima facie reasonable response to, solely, an abnormal experience. But in order to see why a bit of philosophical terminology needs to be introduced.

Let $p$ stand for the content of a thought. If schizophrenics, on the basis of the introspective experience of a thought $p$, believe that someone else is thinking $p$, we can say that they have made an introspection-based error through misidentification: that is, while they are correct about what is being thought, viz. $p$, they have misidentified whom it is that is doing the thinking. If one is to make an error of misidentification, three things are required: (1) an act of identification has to be possible, (2) there has to be an attempt at identification, and (3) one has to fail at that attempt. Making this sort of error could be quite commonplace, for instance, in the case where one is trying to remember which of one's colleagues provided you with some information. However, what is strange about the introspective access case is that we might have thought that when it comes to introspection-based ascriptions, we are immune to error through misidentification (IEM). A philosophical lesson we have learned from Wittgenstein (1958) and Shoemaker (1968) is that when we make introspection-based self-ascriptions we are IEM. In other words, if on the basis of my introspection-based information 
that a thought $p$ is being entertained, I self-ascribe the thought that $p$, it is not possible that I could have made an error. The reason I do not fail at an attempt of identification ( 3 above) is because there is no attempt at identification ( 2 above); and, the reason I do not attempt an identification is because it is not possible to perform an act of identification ( 1 above). ${ }^{9,10}$

What is important to keep in mind is that not having a need to identify who is thinking a thought is the hallmark of introspectionbased self-ascriptions of thought. Coming to know a thought via introspection and not performing an act of identification is what leads to the self-ascription of thought.

However, a report of thought insertion, or alien control, is by definition an error through misidentification. This means that an introspection-based delusional hypothesis that this thought is not mine is the result of a misidentification. Additionally-and this is the essential point-, if there is a misidentification, then it was possible for the subject to perform an act of identification. And given that it is a hallmark of regular thought that no act of identification is required in ascribing a thought to oneself, the mere possibility of performing such an act would give a subject prima facie reason to ascribe the thought to someone else.

We can now see that the delusional hypothesis 'this thought I am introspectively experiencing is not mine' results from an abnormal experience and the reasonable inference just mentioned. Namely, the inference is that if I have to identify whose thought this is, then it is not mine.

This suggests that we can formulate our delusional proto-hypothesis as follows: this thought $p$ that I am introspectively experiencing requires identification. I take this proto-hypothesis to be delusional in that introspection-based thoughts are always one's own. ${ }^{11}$ Nevertheless, I will argue that it is a prima facie reasonable response to the abnormal experience.

And what can we say of this experience? We can say that the abnormal experience which serves as the basis for the proto-hypothesis is such that it raises the issue/possibility of identification. That is, the sufferer of thought insertion, or alien control, must have an abnormal feeling which raises the issue of whose thought, or action, it is that is currently being introspectively experienced. I will now explain why it is this account of the abnormal experience involved in passivity symptoms that should be correlated with a disruption in corollary discharge.

\section{From the bottom, up: correlating abnormal experience with cognitive deficit}

On the corollary discharge model, in the case of regular thought and action, no issue of identification is raised. We can correlate this with a match or near match at the comparator between the efferent copy and reafferent-or in some cases exafferent (i.e. visual feedback)-

\footnotetext{
9 To use one of Wittgenstein's examples, if I have a toothache, the following question would not arise "there is a toothache going on, but is it mine?" Wittgenstein continues, "there is no question of recognizing a person when I say I have a toothache." (Wittgenstein, 1958, 67). And "My use of the word 'I' as the subject of my statement is not due to my having identified as myself something of which I know, or believe, or which to say, that the predicate of my statement applies to it" (Shoemaker, 1968, 558). Immunity to error does not come from any skill in identification. It comes from not having to identify at all.

${ }^{10}$ I should note a difference that is sometimes overlooked by philosophers: schizophrenics are not in violation of Shoemaker's thesis that introspection-based selfascriptions are IEM. This is because in thought insertion and alien control schizophrenics are making ascriptions to others.

${ }^{11}$ Perhaps there are some highly unlikely or rare physiological stories, such that of certain cranial conjoined twins that would, at least for actions if not thoughts, bring the thesis of IEM into question. However, as my claim is only that it is a hallmark of normal thought that no act of identification is required, any deviation from this norm would give strong reason to ascribe one's thought to someone else. But as mentioned, ascribing one's thoughts to someone else does not threaten the IEM thesis, only ascribing someone else's thought oneself.
}

information. In the case of thought insertion or alien control, when there is a delayed efferent copy, reafferent information is still received at the comparator. In the case of hearing a voice or moving one's arm, this reafferent information is quite similar to the information that would be received if someone else was speaking or someone else moved one's arm. So if one still received reafferent information (via proprioception or the auditory loop) without an efferent copy, the sensation would be very similar to one in which someone else was moving one's arm, or speaking. As there is no external correlate for someone else 'moving' my thoughts, the sensation would be even stranger, and one that non-schizophrenics have no analogue for. So thinking, hearing, or moving in cases with a delayed efferent copy and 'on time' reafferent information could result in a feeling that we might describe as raising an issue of identification. The feeling that identification is required in the case of thought insertion and alien control, is a feeling of unfamiliarity in what should be a familiar domain. Additionally, having to perform an act of identification could make it seem as if one's special status with regard to one's own thoughts and actions has been removed. This may lead to what has been called 'diminished self-affection', i.e. a diminished sense of having a first-person perspective (Sass and Parnas, 2003, 2007; Sass et al., 2011).

I have now addressed the second challenge mentioned above: how we should correlate abnormal experience with cognitive deficit in passivity symptoms. I will now return to the first challenge: how to account for delusional hypotheses in thought insertion in terms of the 0 and $1^{\prime}$ factors outlined above.

\section{An outline of a three-factor account of Passivity symptoms}

On the three-factor account, the abnormal aspect of thought insertion, and alien control, is such that it raises an issue of identification. This leads to the formation of a prima facie reasonable response in the form of a delusional proto-hypothesis: this thought $p$ that I am introspectively experiencing requires identification. To explain the next factor $\left(1^{\prime}\right)$, I have argued that this proto-hypothesis can then be modified by a series of fairly reasonable inferences. First, if a thought requires identification, then it is not mine. Second, given that thoughts have thinkers, if this thought is not mine, then it must be someone else's. Third, given the possibility of information in the content of the thought or perhaps auditory or visual imagery present in the thought, it might be assigned to someone else in particular. Finally, since this thought is nevertheless one that I have introspective access to, it seems that a prima facie reasonable delusional hypothesis could be that Bob has inserted this thought that $p$ into my head.

I hope I have presented a compelling reason to adopt a three-factor account of monothematic delusions given its greater explanatory power. More importantly, however, I hope to have presented a compelling picture of how we might correlate abnormal experience with cognitive deficits and the dangers of attempting to directly correlate an abnormal experience with a fully developed delusional hypothesis. I have in several ways tried to accommodate some of Brendan Maher's intuitions by showing that the inferences involved in explaining the $1^{\prime}$ factor of passivity symptoms could solely involve several steps of normal reasoning in response to abnormal experience. Nevertheless, I am in agreement with Davies' and Coltheart's claim that the full adoption and maintenance of a delusional hypothesis will be partially explained by reasoning abnormalities. ${ }^{12}$

\section{Role of the funding source}

None.

\section{Contributors}

None.

12 I will not address factor 2 in this article as that is well beyond the scope of the current project. 


\section{Conflict of interest}

None.

\section{Acknowledgment}

I would like to thank Scott Aikin, David Pitt, Sohee Park, Susanna Siegel, Katy Thakkar, and the anonymous reviewers at Schizophrenia Research for helpful insights and suggestions.

\section{References}

Campbell, J., 1999. Schizophrenia, the space of reasons and thinking as a motor process Monist 82, 609-625.

Colbert, S.M., Peters, E.R., 2002. Need for closure and jumping to conclusions in delusion prone individuals. J. Nerv. Ment. Dis. 190, 27-31.

Coltheart, M., 2013. On the distinction between monothematic and polythematic delusions. Mind Lang. 28, 103-112.

Coltheart, M., Langdon, R., McKay, R., 2007. Schizophrenia and monothematic delusions. Schizophr. Bull. 33, 642-647.

Davies, M., Coltheart, M., 2000. Pathologies of belief. Mind Lang. 15, 1-46.

Davies, M., Coltheart, M., Langdon, R., Breen, N., 2001. Monothematic delusions: toward a two-factor account. Philos. Psychiatry. Psychol. 8, 135-158.

Feinberg, I., 1978. Efference copy and corollary discharge: implications for thinking and its disorders. Schizophr. Bull. 4, 636-640.

Frith, C., 1992. The Cognitive Neuropsychology of Schizophrenia. Erlbaum, Hove, Sussex. Frith, C., Gallagher, S., 2002. Models of the pathological mind. J. Conscious. Stud. 4, 57-80. Frith, C., Blakemore, S., Wolpert, D., 2000. Explaining the symptoms of schizophrenia: abnormalities in the awareness of action. Brain Res. Rev. 31, 357-363.

Garety, P.A., Hemsley, D.R., Wessely, S., 1991. Reasoning in deluded schizophrenic and paranoid patients: biases in performance on a probabilistic inference task. J. Nerv. Ment. Dis. 179, 194-201.

Hoerl, C., 2001. On thought insertion. Physiol. Psychiatry Psychol. 8, 189-200.

Huq, S., Garety, P., Hemsley, D., 1988. Probabilistic judgements in deluded and nondeluded subjects. Q. J. Exp. Psychol. 40A, 801-812.

Jaspers, K., 1923/1963. In: Hoenig, J., Hamilton, M.W. (Eds.), General Psychology Manchester University Press, Manchester.

Jones, S., Fernyhough, C., 2007. Thought as action: inner speech, self-monitoring, and auditory verbal hallucinations. Conscious. Cogn. 16, 391-399.

Langdon, R., Ward, P., Coltheart, M., 2010. Reasoning anomalies associated with delusions in schizophrenia. Schizophr. Bull. 36, 321-330.
Maher, B.A., 1974. Delusional thinking and perceptual disorder. J. Individ. Psychol. 30 98-113.

Maher, B.A., 1992. Delusions: contemporary etiological hypotheses. Psychiatr. Ann. 22, 260-268.

Maher, B.A., 1999. Anomalous experience in everyday life: its significance for psychopathology. Monist 82, 547-570.

Megaw, E., 1972. Directional errors and their correction in a discrete tracking task. Ergonomics 15, 633-643.

Moritz, S., Woodward, T., 2005. Jumping to conclusions in delusional and nondelusional schizophrenic patients. Br. J. Clin. Psychol. 44, 193-207.

Nasrallah, H., 2012. Impaired mental proprioception in schizophrenia. Curr. Psychiatry $11,4-5$.

Sass, L., Parnas, J., 2003. Schizophrenia, consciousness, and the self. Schizophr. Bull. 29 427-444.

Sass, L., Parnas, J., 2007. Explaining Schizophrenia: The Relevance of Phenomenology. In: Chung, M.C., Fulford, K.W.M., Graham, G. (Eds.), Reconceiving schizophrenia. Oxford University Press, Oxford, pp. 63-95.

Sass, L., Parnas, J., Zahavi, D., 2011. Phenomenological psychopathology and schizophrenia: contemporary approaches and misunderstandings. Physiol. Psychiatry Psychol. 18, 1-23.

Seale, M., Aleman, A., Mcguire, P., 2004. Compelling imagery, unanticipated speech, and deceptive memory: neurocognitive models of auditory verbal hallucinations in schizophrenia. Cogn. Neuropsychiatr. 9, 43-72.

Shoemaker, S., 1968. Self-reference and self-awareness. J. Philos. 65, 555-567.

Stone, T., Young, A.W., 1997. Delusions and brain injury: the philosophy and psychology of belief. Mind Lang. 12, 327-364.

Thakkar, K.N., Schall, J.D., Heckers, S., Park, S., 2013. Altered corollary discharge in the saccadic eye movement system of patients with schizophrenia. Poster Presented at the Annual Meeting of the International Congress on Schizophrenia Research. In: Abstracts for the 14th International Congress on Schizophrenia Research. Schizophr. Bull. 39 (Suppl. 1), S276-S277 (Orlando, FL).

Whitford, T, Ford, J. Mathalon, D. Kubicki, M. Shenton, M., 2012. Schizophrenia, myelination, and delayed corollary discharges: a hypothesis. Schizophr. Bull. 38 486-494.

Wittgenstein, L., 1958. The Blue and Brown Books: Preliminary Studies for the 'Philosophical Investigations'. Harper and Row, New York.

Young, H., Bentall, R., 1997. Probabilistic reasoning in deluded, depressed and norma subjects: Effects of task difficulty and meaningful versus non-meaningful material. Psychol. Med. 27, 455-465. 